\title{
Seletividade de Diferentes Herbicidas à Base de Glyphosate a SOJA RR ${ }^{1}$
}

\author{
Selectivity of Different Glyphosate-derived Herbicides to Soybean RR \\ CORREIA, N. M. ${ }^{2}$ e DURIGAN, J.C. ${ }^{2}$
}

\begin{abstract}
RESUMO - Com o objetivo de avaliar a seletividade de variedades de soja transgênica (CD 214 RR e M-SOY 8008 RR) a diferentes herbicidas à base de glyphosate (Roundup Ready, Roundup Transorb, Roundup Original, Roundup WG, Polaris, Gliz, Glifosato Nortox e Trop), foi desenvolvido experimento em condições de campo, no ano agrícola 2005/2006, na Fazenda de Ensino, Pesquisa e Produção da UNESP, campus de Jaboticabal, SP. O delineamento experimental utilizado foi o de blocos ao acaso, num esquema de parcelas subdivididas, com quatro repetições. Os herbicidas foram aplicados na dose de $1,2 \mathrm{~kg} \mathrm{ha}^{-1}$ de equivalente ácido de glyphosate, quando as plantas de soja se encontravam com a segunda folha trifoliolada totalmente expandida. Não foram observados sintomas de intoxicação dos herbicidas nas plantas de soja. Quanto às demais características avaliadas, a interação variedade $\mathrm{x}$ herbicida não foi significativa, indicando que os fatores comportaram-se de forma independente. Entre as variedades, as plantas de M-SOY 8008 RR apresentaram maior altura e número de nós, porém obtiveram menor produtividade de grãos que as de $\mathrm{CD}$ 214 RR, devido ao menor número de grãos por vagem. No tocante aos herbicidas, não houve diferença significativa entre eles, ou seja, eles não influenciaram o desenvolvimento vegetativo e reprodutivo das plantas de soja.
\end{abstract}

Palavras-chave: soja transgênica, fitotoxicidade, Roundup Ready.

ABSTRACT - A field experiment was conducted at the Education, Research and Production Farm of UNESP in Jaboticabal, SP, Brazil, during the agricultural year 2005/2006 to evaluate the selectivity of the glyphosate-tolerant soybeanvarieties (CD214RR andM-SOY 8008 RR) to differentglyphosatederived herbicides (Roundup Ready, Roundup Transorb, Roundup Original, Roundup WG, Polaris, Gliz, Glifosato Nortox, Trop).l. A randomized block in split-plot design was used with four replications. The herbicides had been applied at $1.2 \mathrm{~kg}$ ae $\mathrm{ha}^{-1}$, when the soybean plants had reached the second fully expanded leaf stage. No injury due to herbicide action was observed in the soybean plants. For the other characteristics evaluated, the interaction between varieties and herbicides was not significant, indicating that factors behaved independently. M-SOY $8008 R R$ plants presented higher height and number of nodes, but lower grain yield than CD $214 R R$ plants, due to the lower number of beans per pod ${ }^{1}$. No significant difference was found among the herbicides, which did not influence the vegetative and reproductive development of the soybean plants.

Keywords: transgenic soybean, phytotoxicity, Roundup Ready.

Recebido para publicação em 31.10.2006 e na forma revisada em 17.4.2007.

Eng ${ }^{\circ}-$ Agro $^{-}$Dr., Professor do Dep. de Fitossanidade da UNESP, Campus de Jaboticabal, Via de Acesso Prof. Paulo Donato Castellane, s/n, 14884-900 Jaboticabal-SP, <correianm@fcav.unesp.br>, <durigan@reitoria.unesp.br>. 


\section{INTRODUÇÃO}

A soja tolerante ao glyphosate pode sofrer injúrias ocasionadas pelo herbicida, sob determinadas condições e formulações do sal de glyphosate (Reddy \& Zablatowing, 2003). Entretanto, não há relatos na literatura sobre reduções significativas na produtividade de grãos (Elmore et al., 2001; Krausz \& Young, 2001; Grey \& Raymer, 2002; Reddy \& Zablatowing, 2003).

O sal de glyphosate utilizado no desenvolvimento da soja tolerante foi o de isopropilamina. Nos Estados Unidos, em 1999, o sal de trimetilsulfônio também obteve registro para uso em soja geneticamente modificada. No entanto, em 2001, este foi retirado do mercado e substituído pelo sal de diamônio de glyphosate, também registrado para aplicação em soja transgênica (Reddy \& Zablatowing, 2003).

A formulação sal de trimetilsulfônio de glyphosate, com produto comercial não especificado, ocasionou maior intoxicação visual às plantas de soja, comparada ao sal de isopropilamina (produto comercial Roundup Ready), com notas de 7 e $17 \%$ para as doses de 0,4 e $1,2 \mathrm{~kg} \mathrm{ha}^{-1}$, res pectivamente. Contudo, as plantas afetadas recuperaram-se, apresentando produtividade similar à das pulverizadas com a formulação de isopropilamina (Grey \& Raymer, 2002).

Em outro trabalho, o glyphosate causou clorose mais acentuada nas folhas quando aplicado no estádio R1 da soja, e isso foi intensificado com o aumento das doses utilizadas (Krausz \& Young, 2001). Além disso, a formulação sal de trimetilsulfônio de glyphosate (produto comercial Touchdown 5) ocasionou descoloração das folhas. No entanto, os sintomas permaneceram restritos às folhas que receberam o produto, e as novas apresentaram-se sem injúrias. Neste trabalho, os herbicidas, independentemente da formulação, não afetaram a produtividade de grãos.

O sal de trimetilsulfônio de glyphosate proporcionou amarelecimento e descoloração das folhas de soja entre o primeiro e o segundo dia após a aplicação (Reddy \& Zablatowing, 2003). As injúrias diminuíram com o tempo; a recuperação das plantas foi total aos 14 dias após a segunda aplicação do herbicida. A formulação sal de aminometanamide dihydrogen tetraoxosulface de glyphosate (produto comercial Engame) causou necrose foliar horas após a aplicação. Em ambas as formulações, os sintomas observados ficaram restritos às folhas que interceptaram o jato de pulverização. As folhas novas, emitidas após a aplicação, não apresentaram sintomas.

No Brasil, até o momento, o Roundup Ready, um sal de isopropilamina, é o único herbicida à base de glyphosate registrado para aplicação em soja geneticamente modificada. Entretanto, mesmo não possuindo registro, todos os outros produtos comerciais à base de glyphosate estão sendo utilizados em soja transgência, nas diferentes regiões produtoras do Brasil, não ficando restrito apenas ao Roundup Ready. Por isso, há necessidade de informações sobre possivieis efeitos fitotóxicos desses produtos em soja geneticamente modificada.

Objetivou-se com este trabalho avaliar a seletividade de diferentes herbicidas à base de glyphosate a variedades de soja transgênica.

\section{MATERIAL E MÉTODOS}

O experimento foi desenvolvido em condições de campo, no ano agrícola 2005/2006, na Fazenda de Ensino, Pesquisa e Produção da UNESP, campus de Jaboticabal, SP.

O delineamento experimental utilizado foi o de blocos ao acaso, num esquema de parcelas subdivididas, com quatro repetições. Foram mantidos duas variedades de soja nas parcelas (CD 214 RR e M-SOY 8008 RR), oito herbicidas (Roundup Ready, Roundup Transorb, Roundup Original, Roundup WG, Polaris, Gliz, Glifosato Nortox e Trop) e uma testemunha sem aplicação (mantida capinada até o fechamento do dossel das plantas) nas subparcelas.

Com base em análise de solo e na necessidade nutricional da cultura, fez-se a recomendação de adubação, que consistiu da aplicação de 300 kg ha-1 de 04-30-15 no sulco de semeadura. Foi feita a inoculação com 2 g do inoculante Biomax por $\mathrm{kg}$ de semente.

A soja foi semeada na segunda semana de dezembro, em sistema de cultivo mínimo, com gradagem leve do solo, cerca de 60 dias antes 
da semeadura, e dessecação das plantas daninhas emergidas nesse período, com $0,72 \mathrm{~kg} \mathrm{ha}^{-1}$ de equivalente ácido de glyphosate. A semeadura foi realizada a uma profundidade de $5 \mathrm{~cm}$, com $0,45 \mathrm{~m}$ de distância entre linhas e 25 sementes por metro.

As parcelas (variedades de soja) apresentaram 3,15 m de largura e $45 \mathrm{~m}$ de comprimento, e as subparcelas (herbicidas à base de glyphosate), 3,15 $\mathrm{m}$ de largura e $5 \mathrm{~m}$ de comprimento. Quatro linhas centrais com $4 \mathrm{~m}$ de comprimento perfaziam a área útil das subparcelas, totalizando $7,2 \mathrm{~m}^{2}$.

Os herbicidas foram aplicados na dose de $1,2 \mathrm{~kg} \mathrm{ha}^{-1}$ de equivalente ácido de glyphosate, quando as plantas de soja se encontravam com a segunda folha trifoliolada totalmente expandida. Foi utilizado pulverizador costal, à pressão constante (mantida pelo $\mathrm{CO}_{2}$ comprimido) de 2,24 $\mathrm{kgf} \mathrm{cm}^{-2}$, munido de barra com seis bicos de jato plano ("leque") 110.02 , espaçados de $0,5 \mathrm{~m}$, com consumo de calda equivalente a $200 \mathrm{~L} \mathrm{ha}^{-1}$. No momento da aplicação, foram registrados $27,1{ }^{\circ} \mathrm{C}$ de temperatura do ar; $25,1{ }^{\circ} \mathrm{C}$ de temperatura do solo; $87 \%$ de umidade relativa do ar; ventos leves com velocidade de $2,0 \mathrm{~km} \mathrm{~h}^{-1}$; e nebulosidade variável, em torno de $80 \%$.

Aos 5, 10 e 15 dias após a aplicação (DAA) foram realizadas avaliações visuais de intoxicação nas plantas de soja, atribuindo-se notas em porcentagem para cada unidade experimental. Determinou-se, aos 15, 35 e 93 DAA, a altura das plantas $(\mathrm{cm})$, considerando-se a distância entre o colo e a extremidade da haste principal. Também, aos 35 DAA, fez-se a contagem do número de nós da haste principal e a quantificação da matéria seca da parte aérea das plantas de soja (g planta ${ }^{-1}$ ). Esses valores foram tomados de 10 plantas em linha, na área útil da unidade experimental.

No momento da colheita dos grãos, fez-se a determinação do número de vagens por planta, número de grãos por vagem, peso de grãos por planta(g) e peso de 100 grãos (g). Para isso, foram coletadas, em linha, cinco plantas de soja da área útil de cada unidade experimental. Para determinação da produção de grãos (kg ha1), por unidade experimental, foram colhidas manualmente três linhas com quatro metros de comprimento, as quais foram trilhadas, e a umidade dos grãos foi corrigida para $13,5 \%$.
Os resultados obtidos foram submetidos ao teste $\mathrm{F}$ da análise de variância. Os efeitos das variedades e dos herbicidas, quando significativos, foram comparados pelo teste de Tukey a $5 \%$. O programa estatístico utilizado foi o SISVAR.

\section{RESULTADOS E DISCUSSÃO}

Nas três avaliações, os herbicidas não provocaram efeitos fitotóxicos que pudessem ser visualizados nas plantas de soja das duas variedades estudadas. Para as demais características avaliadas, a interação variedade $\mathrm{x}$ herbicida não foi significativa, indicando que os fatores comportaram-se de forma independente.

Entre as variedades (Tabela 1), embora com maior altura e número de nós, as plantas de M-SOY 8008 RR apresentaram menor produção de grãos, comparadas às de CD 214 RR, devido ao menor número de grãos por vagem. Os resultados podem ser justificados por diferenças genéticas entre os materiais, não podendo ser atribuídos aos herbicidas utilizados, visto que as plantas da testemunha sem aplicação também apresentaram o mesmo comportamento. Os duas variedades testados possuem ciclo médio em torno de 120 dias e ambos são recomendados para o Estado de São Paulo.

Quanto aos herbicidas, não houve diferença significativa entre eles, ou seja, não influenciaram o desenvolvimento vegetativo e reprodutivo das plantas de soja. Resultados similares foram obtidos por Vidrine et al. (2002), cuja aplicação de sal de isopropilamina de glyphosate (p. c. Roundup Ultra), nas doses de $0,42,0,56,0,70$ e $0,84 \mathrm{~kg} \mathrm{ha}^{-1}$, não afetou as plantas de soja.

O contrário foi observado por Reddy \& Zablotowicz (2003) com o sal de trimetilsulfônio de glyphosate (produto comercial Touchdown) e o sal de aminometanamide dihydrogen tetraoxosulface de glyphosate (produto comercial Engame), que causaram injúrias às plantas de soja, com notas variando de 29 a $38 \%$, dois dias após a aplicação. Contudo, houve total recuperação das plantas. As formulações de glyphosate não afetaram o conteúdo de clorofila, a matéria seca da parte aérea e da raiz e o 
Tabela 1 - Altura de plantas (AP), número de nós (NN) por planta, matéria seca da parte aérea (MSPA), peso de 100 grãos (P100), número de vagens (NV) por planta, número de grãos (NG) por vagem, peso de grãos (PG) por planta e produtividade de grãos (PG) de duas variedades de soja RR, pulverizadas com herbicidas à base de glyphosate, além da testemunha sem herbicida. UNESP/campus de Jaboticabal-SP, 2005/2006

\begin{tabular}{|c|c|c|c|c|c|c|c|c|c|c|}
\hline \multirow{2}{*}{ Herbicidas } & \multicolumn{3}{|c|}{$\mathrm{AP}(\mathrm{cm}) / \mathrm{DAA}$} & \multirow{2}{*}{$\begin{array}{c}\mathrm{NN} \\
\text { planta }^{-1}\end{array}$} & \multirow{2}{*}{$\begin{array}{c}\text { MSPA } \\
\left(\text { g planta }^{-1}\right)\end{array}$} & \multirow{2}{*}{$\begin{array}{l}\mathrm{P} 100 \\
(\mathrm{~g})\end{array}$} & \multirow{2}{*}{$\begin{array}{c}\mathrm{NV} \\
\text { planta }^{-1}\end{array}$} & \multirow{2}{*}{$\begin{array}{c}\mathrm{NG} \\
\text { vagem }^{-1}\end{array}$} & \multirow{2}{*}{$\begin{array}{c}\text { PG } \\
\text { planta }^{-1}(\mathrm{~g})\end{array}$} & \multirow{2}{*}{$\begin{array}{c}\mathrm{PG} \\
\left(\mathrm{kg} \mathrm{ha}^{-1}\right)\end{array}$} \\
\hline & 15 & 35 & 93 & & & & & & & \\
\hline Roundup Ready & 34,40 & 77,44 & 78,52 & 14,10 & 13,24 & 14,30 & 49,12 & 1,86 & 12,78 & 3109,62 \\
\hline Roundup Transorb & 34,82 & 74,99 & 78,21 & 13,78 & 12,81 & 14,33 & 50,68 & 1,79 & 13,06 & 3244,59 \\
\hline Roundup Original & 34,46 & 79,16 & 77,48 & 13,65 & 11,58 & 16,04 & 45,73 & 1,73 & 12,11 & 3333,22 \\
\hline Roundup WG & 35,45 & 79,59 & 78,04 & 13,70 & 13,04 & 14,09 & 40,65 & 1,81 & 10,45 & 3344,67 \\
\hline Polaris & 34,40 & 80,34 & 81,39 & 14,13 & 12,66 & 14,18 & 45,25 & 1,88 & 11,97 & 3353,69 \\
\hline Gliz & 34,75 & 79,68 & 74,98 & 13,75 & 11,86 & 14,28 & 45,22 & 1,83 & 11,55 & 3333,31 \\
\hline Glifosato Nortox & 34,41 & 76,29 & 78,29 & 13,63 & 12,37 & 13,85 & 45,57 & 1,94 & 12,07 & 3223,35 \\
\hline Trop & 34,12 & 77,01 & 77,09 & 14,18 & 12,76 & 15,75 & 45,70 & 1,71 & 12,14 & 3144,94 \\
\hline Test. s/ herbicida & 34,66 & 77,08 & 81,28 & 14,57 & 13,78 & 14,39 & 45,98 & 1,83 & 11,92 & 3237,22 \\
\hline d.m.s. & 2,66 & 10,55 & 8,72 & 1,10 & 4,28 & 2,89 & 17,49 & 0,29 & 5,21 & 448,06 \\
\hline \multicolumn{11}{|l|}{ Cultivares } \\
\hline CD 214 RR & $30,43 \mathrm{~b}$ & $61,66 \mathrm{~b}$ & $63,92 \mathrm{~b}$ & $12,77 \mathrm{~b}$ & 12,27 & 14,39 & 45,32 & $1,88 \mathrm{a}$ & 11,88 & 3442,31 a \\
\hline M-SOY 8008 RR & $38,79 \mathrm{a}$ & $94,25 \mathrm{a}$ & $92,81 \mathrm{a}$ & $15,11 \mathrm{a}$ & 13,08 & 14,77 & 46,66 & $1,76 \mathrm{~b}$ & 12,13 & $3074,26 \mathrm{~b}$ \\
\hline d.m.s. & 1,94 & 6,29 & 5,21 & 0,39 & 1,41 & 0,93 & 5,07 & 0,08 & 1,13 & 142,09 \\
\hline $\mathrm{CV}(\%)$ (parcela) & 7,46 & 10,77 & 8,86 & 3,79 & 14,84 & 8,52 & 14,71 & 6,10 & 12,57 & 5,81 \\
\hline CV (\%)(subparcela) & 4,73 & 8,34 & 6,85 & 4,89 & 20,79 & 12,06 & 23,43 & 9,93 & 26,70 & 8,47 \\
\hline
\end{tabular}

DAA - dias após a aplicação dos herbicidas.

Médias seguidas pela mesma letra não diferem significativamente entre si pelo teste de Tukey a 5\%.

número de nódulos, mas reduziram a biomassa de nódulos de 21 a 38\%. Os níveis de glyphosate nos nódulos das plantas variaram de 39 a $147 \mathrm{ng} \mathrm{g}^{-1}$ (matéria seca). O índice de leghemoglobina foi reduzido em torno de $10 \%$. Os autores concluíram que os sintomas de intoxicação nas plantas de soja e a inibição no desenvolvimento de nódulos podem ocorrer, porém a soja possui capacidade de recuperação dos efeitos do glyphosate, sem prejuizos à produtividade de grãos.

Trabalhando com algodão e milho tolerantes ao glyphosate, Parker et al. (2005) estudaram a toxicidade de 10 herbicidas à base de glyphosate (sete sais de isopropilamina, dois sais de potássio e um sal de diamônio). Esses autores constataram que os herbicidas não ocasionaram intoxicação visual às plantas de milho, o mesmo ocorrendo para produtividade de grãos. Contudo, o algodão tratado com ClearOut 41 Plus (sal de isopropilamina) e Roundup Weathermax (sal de potássio), ambos a $1,68 \mathrm{~kg} \mathrm{ha}^{-1}$, causaram injúrias às plantas. Os sintomas apresentaram-se menos de
24 horas após a aplicação, mas ficaram restritos às folhas que receberam a calda pulverizada. As injúrias observadas não foram refletidas na produtividade e nas propriedades da fibra do algodão.

No presente trabalho, todos os herbicidas estudados são formulados como sais de isopropilamina de glyphosate, com exceção de Roundup WG, cuja formulação é sal de amônio. Os resultados mostraram que as formulações não causaram injúrias às plantas de soja. Apesar da presença de diferentes surfatantes e inertes nas suas composições, os herbicidas apresentaram comportamentos similares em ambas as variedades de soja avaliadas.

Com base nos resultados obtidos, pode-se concluir que os herbicidas à base de glyphosate (Roundup Ready, Roundup Transorb, Roundup Original, Roundup WG, Polaris, Gliz, Glifosato Nortox e Trop) não causaram injúrias às plantas de soja (variedades CD 214 RR e M-SOY 8008RR), com pleno desenvolvimento vegetativo e reprodutivo destas. 


\section{LITERATURA CITADA}

ELMORE, R. W. et al. Glyphosate-resistant soybean cultivar response to glyphosate. Agron. J., v. 93, n. 2, p. 404-407, 2001 .

GREY, T. L.; RAYMER, P. Sicklepod (Senna obtusifolia) and red Morningglory (Ipomoea cocinea) control in glyphosate-resistant soybean with narrow rows and postemergence herbicide mixtures. Weed Technol., v. 16, n. 3, p. 669-674, 2002.

KRAUSZ, R. F.; YOUNG, B. G. Response of glyphosateresistant soybean (Glycine max) to trimetylsulfonium and isopropylamine salts of glyphosate. Weed Technol., v. 15, n. 4 , p. $745-749,2001$.
PARKER, R. G. et al. Comparison of glyphosate products in glyphosate-resistant cotton (Gossypium hirsutum) and corn (Zea mays). Weed Technol., v. 19, n. 4, p. 796-802, 2005.

REDDY, N. K.; ZABLOTOWICZ, R. M. Glyphosateresistant soybean response to various salts of glyphosate and glyphosate accumulation in soybean nodules. Weed Sci., v. 51, n. 4, p. 496-502, 2003.

VIDRINE, P. R. et al. Evaluation of reduced rates of glyphosate and chlorimuron in glyphosate-resistant soybean (Glycine max). Weed Technol., v. 16, n. 4, p. 731-736, 2002. 